\title{
Metastatic breast carcinoma of the coracoid process: two case reports
}

\author{
Eric C Benson ${ }^{1 * \dagger}$, Darren S Drosdowech ${ }^{2}$
}

\begin{abstract}
Background: The coracoid process of the scapula is a rare site of involvement for metastatic disease or for primary tumors. We are unaware of any reports in the literature of pathologic coracoid process fractures and only one report of metastatic disease to the coracoid.
\end{abstract}

Methods and Results: In this case report, we present two cases with metastatic breast carcinoma of the coracoid process, one of which presented with a pathologic fracture of the coracoid.

Conclusions: An orthopaedic surgeon must be aware of the potential for metastatic disease to the coracoid as they may be the first medical provider to encounter evidence of malignant disease.

\section{Introduction}

The coracoid process of the scapula is a rare site of involvement for metastatic disease or for primary tumors. Bone metastases are common in patients with breast carcinoma, with an incidence as high as $73 \%$ (range 47-85\%) [1]. The exact mechanism of metastases to bone remains unknown.

We are unaware of any reports in the literature of pathologic coracoid process fractures, and only one report of metastatic disease to the coracoid [2]. We present the cases of two patients with metastatic breast carcinoma of the coracoid process, one of which presented with a pathologic fracture of the coracoid. We informed the patients or their families that the data concerning their cases would be submitted for publication, and they consented.

\section{Case 1}

A 40-year-old, right-hand dominant female who had a known history of right breast carcinoma presented to our clinic for evaluation for open biopsy of a lesion at the base of the coracoid. Four months prior to clinic presentation, she underwent right breast lumpectomy and lymph node dissection. Surgical pathology revealed invasive mammary

\footnotetext{
* Correspondence: ebenson@salud.unm.edu

+ Contributed equally

${ }^{1}$ Department of Orthopaedic Surgery and Rehabilitation, Division of Shoulder and Elbow Surgery, MSC10 - 5600, 1 University of New Mexico, Albuquerque, NM 87131, USA
}

carcinoma, SBR grade 2 with no involvement of the lymph nodes. Resection margins were negative. She was Her-2neu negative, estrogen receptor negative, and progesterone receptor positive. A bone scan revealed increased uptake at the eighth thoracic vertebra and in the region of the coracoid in the right shoulder. Further CT imaging of both regions indicated a fracture through the transverse process of $\mathrm{T} 8$, though the patient was asymptomatic at this level and had a prior history of a fall from a horse that correlated with this finding. There was no history of any shoulder pain resulting from or subsequent to that fall. CT imaging of the scapula showed osteolytic change at the base of the coracoid. Radiographs and relevant CT scan images are shown (Figures 1 and 2). She had received the first cycle of adjuvant chemotherapy with FEC-100 but further cycles were discontinued until further information regarding the possible sites of metastases was collected. Instead, she was placed on Tamoxifen and Clodronate. She was otherwise healthy and took no other medications.

On physical exam there was no palpable mass in the region of the right shoulder, no skin discoloration or changes, and her range of motion and strength were normal. She was nontender to palpation over the coracoid process. She had no tenderness to palpation over T8 or elsewhere throughout the spine. Upper and lower extremity neurovascular exam showed no focal deficits.

The patient consented to open biopsy of the coracoid and was taken to the operating room. Through a deltopectoral approach, the coracoid was identified and 


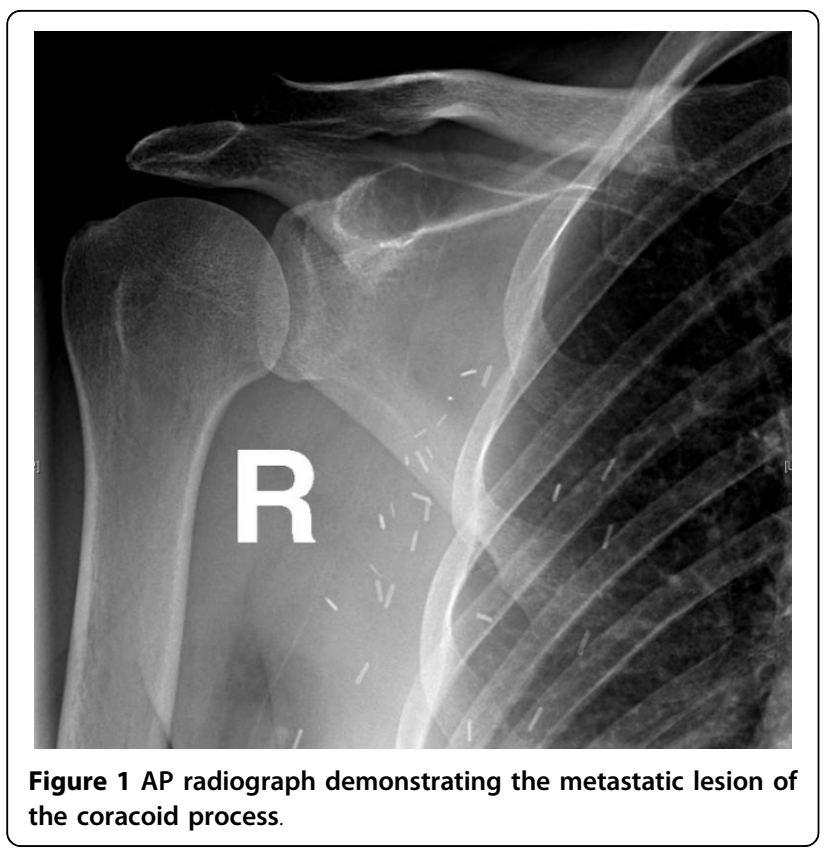

biopsy specimens from the lesion at the base of the coracoid were sent to pathology for frozen section and permanent sections. The intra-operative frozen section was positive for adenocarcinoma.

The patient had no complications following the biopsy and the surgical pathology report confirmed the lesion was a metastatic breast adenocarcinoma. The immunohistochemical stains showed moderately to strongly positive progesterone receptors in about $15 \%$ and moderately positive estrogen receptors in about $2 \%$ of malignant cells.

Approximately twenty months after her initial lumpectomy, the patient underwent right partial mastectomy for recurrent carcinoma. At most recent follow-up,

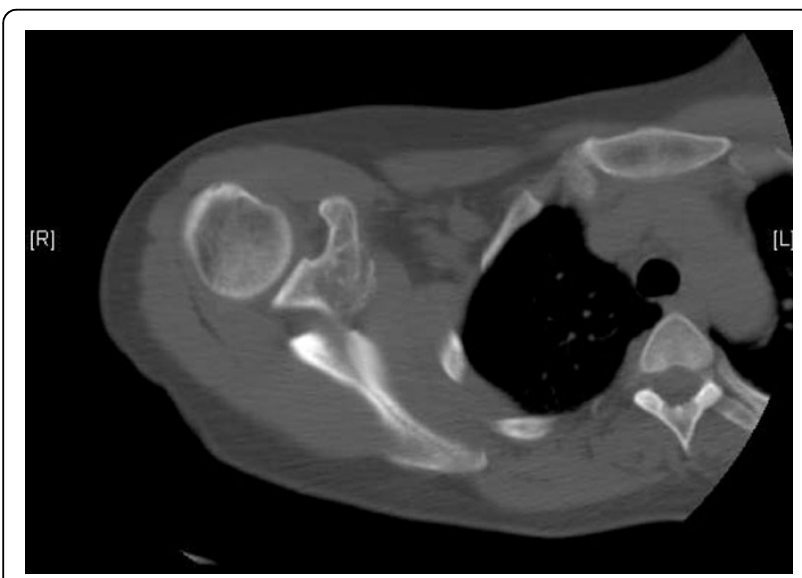

Figure $2 \mathrm{CT}$ scan showing the metastatic lesion at the base of the coracoid. two years after initial diagnosis, she is doing well with no evidence of local recurrence or progression of metastatic disease.

\section{Case 2}

A 23-year-old, right-hand dominant female sports coach fell backwards onto outstretched arms while snowboarding one week prior to presentation. She noted immediate left shoulder pain, was seen at on outside Emergency Department, and was referred to orthopedics for management of her shoulder injury. She sustained no other injuries in the fall. She noted no other previous complaints with regard to her left shoulder. She took Naprosyn for pain relief. Over the months leading up to the fall, she was treated with NSAIDs at another center for chest wall pain presumed to be osteochondritis. Otherwise, she had no significant findings in review of her past medical history. Prior surgeries included removal of a Bartholin's cyst.

Physical examination revealed isolated point tenderness over the tip of the coracoid. She had full neck, shoulder, and elbow range of motion with some discomfort at the terminal range of internal and external rotation of the shoulder. Her neurovascular exam showed no focal deficits.

Radiographs showed a nondisplaced fracture of the coracoid (Figures 3 and 4). These were compared to her outside films taken immediately after her fall and showed no interval change in position of the fragment.

We recommended non-operative management of this stable injury. Short-term immobilization using a sling followed by initiation of physiotherapy was arranged. Gentle strengthening was to start after approximately four to six weeks as tolerated.

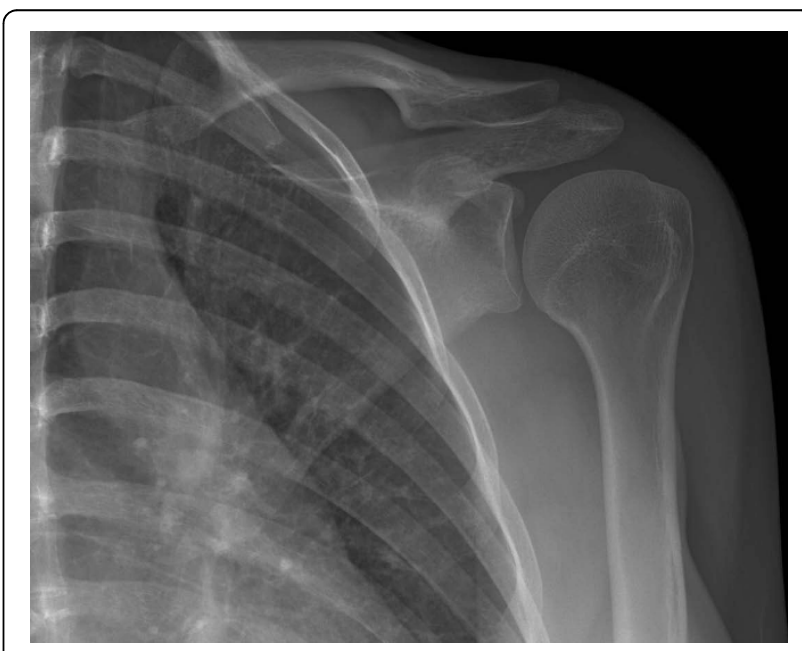

Figure 3 AP radiograph of the nondisplaced pathologic coracoid process fracture. 


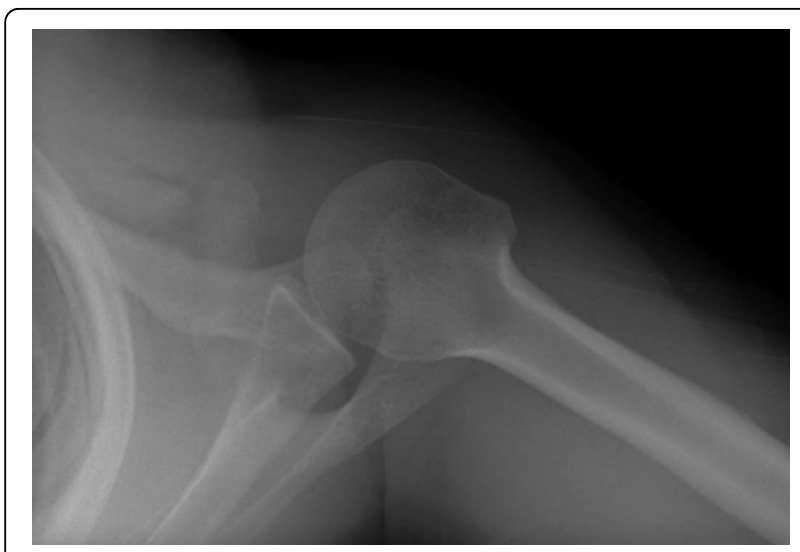

Figure 4 Axillary radiograph showing the pathologic coracoid fracture.

Tragically, this previously healthy, active, young woman was admitted to an outside facility only two weeks later with hypercalcemia, multiple sites of bone metastases noted on skeletal survey, and an abnormal liver scan. She was diagnosed with metastatic adenocarcinoma of the left breast. In addition to the coracoid, she had multiple metastatic lesions in her thoracic spine and bilateral femurs as well as brain and liver metastases. Over the course of the following four months she suffered from encephalopathy, SIADH, leptomeningeal carcinomatosis, and eventually passed away in her home receiving palliative care.

Though the patient's mechanism of injury was consistent with an acute coracoid fracture, in retrospect her injury was likely a pathologic fracture secondary to her metastatic breast adenocarcinoma.

\section{Discussion}

Tumors of the coracoid process are rare. We could only identify one report of a metastatic lesion to the coracoid using a PubMed search of the literature [2]. Primary bone tumors of the coracoid include osteoid osteoma, osteosarcoma, giant cell tumor, chondrosarcoma, capillary hemangioma, aneurysmal bone cyst, lymphoma, and plasmacytoma [3]. In our PubMed literature search, we found no reports of pathologic coracoid fractures.

Breast cancer's propensity to metastasize to bone is not clearly understood. Batson described the valveless venous plexus commonly thought to contribute to the spread of breast and prostate carcinoma to sites in the axial and appendicular skeleton [4]. More recently, studies suggest some of the mechanisms for bone destruction once tumor cells have gained access to a distant site. These include osteoclast activating factors such as parathyroid hormone-related protein (PTH-rP), tumor necrosis factor (TNF) $\alpha$ and $\beta$, epidermal growth factor (EGF), and prostaglandins [5]. These changes to the bone architecture lead to structural weakness, and typically, the radiographic appearance of breast metastases to bone is one of mixed osteoblastic and osteolytic appearance.

Often, the orthopaedic surgeon is the first medical provider to encounter evidence of malignant disease and as such must be aware of potential sites of involvement. When interpreting radiographs, especially in an area as difficult as the coracoid, it is important to maintain an index of suspicion for underlying pathologic processes, especially since isolated fractures of the coracoid process are rare [6-23]. When present, it may be difficult to identify the bony architecture at the fracture site secondary to overlying structures. It may be prudent to obtain extra imaging to clearly show the bony characteristics of the injury. A 20 degree posterior oblique film with 20 degrees of cephalad angulation can show coracoid fractures and bone morphology more clearly if other views are inconclusive [24]. CT scans may also be useful.

The role of the orthopaedic surgeon may also include recommendations for bisphosphonate use. In concert with the consulting medical oncologist, administering bisphosphonates may reduce the risk of skeletal complications in patients receiving systemic therapy who have lytic bone metastatic lesions secondary to breast cancer $[25,26]$.

The coracoid process of the scapula is a rare site of acute isolated trauma, primary tumors, or of metastatic disease. We present what we believe to be the first reported case of a pathologic fracture of the coracoid in one of two patients who presented with metastatic breast carcinoma of the coracoid. Although rare, orthopaedic surgeons must be aware of the potential for a pathologic process involving the coracoid.

\section{Consent}

Informed consent was obtained from the patient or patient's family for publication of this case report and all accompanying radiographic images.

\section{Author details}

${ }^{1}$ Department of Orthopaedic Surgery and Rehabilitation, Division of Shoulder and Elbow Surgery, MSC10 - 5600, 1 University of New Mexico, Albuquerque, NM 87131, USA. ${ }^{2}$ University of Western Ontario, Division of Orthopedic Surgery, Hand and Upper Limb Centre, St. Joseph's Health Centre, 268 Grosvenor St, London, ON N6A 4V2, Canada.

\section{Authors' contributions}

DD performed all clinical evaluations and interactions with the patients. EB reviewed the case files, contacted the patients' or patients' families to obtain informed consent, and prepared the manuscript and image files. Both EB and DD read, revised, and approved the final manuscript.

\section{Competing interests}

The authors declare that they have no competing interests.

Received: 6 May 2009 Accepted: 26 March 2010 Published: 26 March 2010 


\section{References}

1. Galasko CSB: The anatomy and pathways of skeletal metastases. Bone Metastasis Boston: GK HallWeiss L, Gilbert AH 1981, 49.

2. Kato $Y$, Numata A, Wada N, Iwata T, Saga Y, Hashimoto H, Kakizaki H: A case of metastatic renal cell carcinoma to the ovary. Hinyokika Kiyo 2006, 52:923-7.

3. Ogose A, Sim FH, O'Connor MI, Unni KK: Bone Tumors of the coracoid process of the scapula. Clin Orthop Relat Res 1999, 358:205-214.

4. Batson OV: The role of the vertebral veins in metastatic process. Ann Intern Med 1942, 16:38.

5. Travers MT, Barrett-Lee PJ, Berger U, Luqmani YA, Gazet JC, Powles TJ, Coombes RC: Growth factor expression in normal, benign and malignant breast tissue. Br Med J 1988, 296:1621.

6. Asbury S, Tennent TD: Avulsion fracture of the coracoid process: a case report. Injury 2005, 36:567-568.

7. Ogawa K, Yoshida A, Takahashi M, Ui M: Fractures of the coracoid process. J Bone Joint Surg Br 1997, 79:17-19.

8. Guiral J, Real JL, Curto JM: Isolated fracture of the coracoid process of the scapula. Acta Orthop Belg 1996, 62:60-61.

9. Eyres KS, Brooks A, Stanley D: Fractures of the coracoid process. J Bone Joint Surg Br 1995, 77:425-428.

10. Bauer G, Fleischmann W, Dussler E: Displaced scapular fractures: indication and long-term results of open reduction and internal fixation. Arch Orthop Trauma Surg 1995, 114:215-219.

11. Gil JF, Hayday A: Isolated injury of the coracoid process: case report. Trauma 1991, 31:1696-1697.

12. Martin-Herrero T, Rodriguez-Merchan C, Munuera Martinez L: Fractures of the coracoid process: presentation of seven cases and review of the literature. J Trauma 1990, 30:1597-1599.

13. Kopecky KK, Bies JR, Ellis JH: CT diagnosis of fracture of the coracoid process of the scapula. Comput Radiol 1984, 8:325-327.

14. Goldberg RP, Vicks B: Oblique angled view for coracoid fractures. Skeletal Radiol 1983, 9:195-197.

15. Heyse-Moore GH, Stoker DJ: Avulsion fractures of the scapula. Skeletal Radiol 1982, 9:27-32.

16. Zilberman Z, Rejovitzky R: Fracture of the coracoid process of the scapula. Injury 1981, 13:203-206.

17. Mariani PP: Isolated fracture of the coracoid process in an athlete. Am J Sports Med 1980, 8:129-130.

18. Froimson Al: Fracture of the coracoid process of the scapula. $J$ Bone Joint Surg Am 1978, 60:710-711.

19. DeRosa GP, Kettelkamp DB: Fracture of the coracoid process of the scapula: case report. J Bone Joint Surg Am 1978, 59:696-697.

20. Sandrock AR: Another sports fatigue fracture. Stress fracture of the coracoid process of the scapula. Radiology 1975, 117:274.

21. Boyer DW Jr: Trapshooter's shoulder: stress fracture of the coracoid process of the scapula. J Bone joint Surg Am 1975, 57:862.

22. Rounds RC: Isolated Fracture of the Coracoid Process. J Bone Joint Surg Am 1949, 31:662-663.

23. Petty $\mathrm{OH}$ : Fracture of the coracoid process of the scapula caused by muscular action: with report of case. Ann Surg 1907, 45:427-430.

24. Goldberg RP, Vicks B: Oblique angled view for coracoid fractures. Skeletal Radiol 1983, 9:195-197.

25. Hortobagyi GN, Theriault RL, Lipton A, Porter L, Blayney D, Sinoff C, Wheeler H, Simeone JF, Seaman JJ, Knight RD, Heffernan M, Mellars K, Reitsma DJ: Long-term prevention of skeletal complications of metastatic breast cancer with pamidronate: Protocol 19 Aredia Breast Cancer Study Group. J Clin Oncol 1998, 16:2038-2044.

26. Theriault RL, Lipton A, Hortobagyi GN, Leff R, Glück S, Stewart JF, Costello S, Kennedy I, Simeone J, Seaman JJ, Knight RD, Mellars K, Heffernan M, Reitsma DJ: Pamidronate reduces skeletal morbidity in women with advanced breast cancer and lytic bone lesions: A randomized, placebocontrolled trial. J Clin Oncol 1999, 17:846-854.

doi:10.1186/1749-799X-5-22

Cite this article as: Benson and Drosdowech: Metastatic breast carcinoma of the coracoid process: two case reports. Journal of Orthopaedic Surgery and Research 2010 5:22.

\section{Submit your next manuscript to BioMed Central and take full advantage of:}

- Convenient online submission

- Thorough peer review

- No space constraints or color figure charges

- Immediate publication on acceptance

- Inclusion in PubMed, CAS, Scopus and Google Scholar

- Research which is freely available for redistribution

Submit your manuscript at www.biomedcentral.com/submit
Biomed Central 